\title{
A transferência na clínica psicanalítica com crianças
}

The transference in psychoanalytic clinic with children

1 Luciana Jaramillo Caruso Azevedo lucianajaramillo@msn.com

1 PUC Rio de JAneiro

\section{Resumo}

Partindo de observações provenientes da clínica psicanalítica com crianças, este estudo propõe uma discussão teórica acerca de determinadas especificidades pertencentes a esse campo do saber. Entre as particularidades que incidem na clínica e que tornam o trabalho do analista cada vez mais complexo, destacamos o manejo da transferência e o lugar designado aos pais durante o processo analítico. Cabe salientar que a marca da diferença entre a análise de crianças e de adultos não se restringe a um aspecto técnico, pois essa diferença aponta para uma questão central dos próprios fundamentos da psicanálise, isto é, a transferência. Na análise de crianças, a transferência opera de modo diferente, tendo em vista que os pais da realidade se fazem presentes durante todo tratamento. Por serem pilares dessa clínica, fundamentais para o estabelecimento e continuidade do trabalho com crianças e por não haver ações previamente instituídas, compreendemos ser indispensável discutir sobre o manejo transferencial nesse contexto. Para atingir o objetivo deste estudo, inicialmente será discutida a transferência e o lugar dos pais na transferência. Em seguida, serão apresentadas algumas reflexões sobre o manejo transferencial. Posteriormente, será indicada a identificação projetiva como um importante elemento a ser considerado no manejo da transferência.

Palavras-chave:

Psicanálise. Crianças. Transferência. Identificação projetiva.

\begin{abstract}
Taking into account observations from the psychoanalytic clinics with children, this study proposes a theoretical discussion about certain features belonging to this field of knowledge. Among the particularities that affect the clinics and that make the analyst's work increasingly complex, we may highlight the management of the transference and the place assigned to parents during the analytical process. It is worth emphasizing that the mark of the difference between the analyses of children and of adults is not limited to a technical aspect, but this difference signalizes a core issue of the very cornerstones of psychoanalysis, i.e., the transference. When analyzing children, the transference works differently, bearing in mind that the parents of reality are present during the whole period of treatment. Because they are pillars of this clinic, essential for the establishment and continuity of the work with children, and for not having previously established actions, we understand that it is imperative to discuss the transference management in this context. In order to reach the aim of this study, we will firstly discuss transference and the place of parents in transference. Afterward, we will introduce some reflections on transference management. Subsequently, we will indicate the projective identification as an important element to be considered in transference management.
\end{abstract}

\section{Keywords:}

Psychoanalysis. Children. Transference. Projective identification. 


\section{INTRODUÇÃO}

O trabalho psicanalítico com crianças apresenta especificidades que demandam constantemente o aprofundamento deste estudo. A presença dos pais desde o início do tratamento, a escolha do psicanalista, a abertura para a escuta dos pais durante as entrevistas preliminares e o trabalho com estes, quando for necessário, no decorrer do tratamento da criança, provocam um considerável movimento transferencial que não tem como ser ignorado. De acordo com Faria (2016), mais do que um traço particular do tratamento de crianças, a presença dos pais define uma especificidade dessa clínica, posto que o manejo e a intervenção se fazem necessários.

O fato de a criança ser trazida à análise estabelece não apenas uma necessidade de reflexão sobre o lugar dos pais como também sobre o manejo de sua presença. Assim, o lugar que o psicanalista designa aos pais no tratamento dos filhos, para além de uma questão técnica, é revelador das concepções teóricas que fundamentam a prática clínica. É uma posição ética que sustenta que o emaranhado que envolve a criança e seu sintoma exige um manejo orientado pela concepção de sujeito e de inconsciente que embasa toda escuta analítica (FARIA, 2016).

Nesse sentido, Dolto (2004) afirma que os fatos vividos por uma criança não são exatamente como poderiam ser testemunhados por adultos e sim consistem em um conjunto formado pelas percepções da criança e o valor simbólico que se desprende do sentido que essas percepções assumem para o narcisismo do sujeito. Por sua vez, Mannonni (2004) esclarece que a criança que é levada ao consultório do psicanalista está situada em uma família e carrega o peso da história de cada um de seus pais. Em função disso, compreendemos que o cerne do atendimento às crianças vai muito além das dificuldades escolares, dos sintomas escolares ou médicos, apesar de incluí-los. 0 trabalho do psicanalista com crianças deve, primordialmente, estar orientado para a escuta do sujeito do inconsciente e apontar para os impasses que dificultam o desenvolvimento da criança. O processo analítico permite que a criança possa ser sujeito dos seus próprios desejos, desembaraçados, e não alienados aos fantasmas parentais.

A partir desse panorama, o presente artigo visa estabelecer uma articulação entre o manejo da transferência na clínica com crianças e o lugar designado aos pais durante o processo analítico. Para atingir o objetivo deste estudo, inicialmente será discutida a transferência e o lugar dos pais. Em seguida, serão apresentadas algumas reflexões sobre o manejo transferencial. Posteriormente, será indicada a identificação projetiva como um importante elemento a ser considerado no manejo. A transferência, compreendida como via régia para o processo analítico, será estudada com base nos textos freudianos e, em seguida, a identificação projetiva assumirá relevo como um importante elemento a ser considerado no manejo da transferência.

\subsection{Sobre a transferência e o lugar dos pais}

Para iniciarmos este estudo, salientamos que o termo transferência não está circunscrito ao vocabulário psicanalítico. A noção de transferência designa e abarca um sentido de transporte ou deslocamento. Entretanto, em se tratando do campo psicanalítico, por transferência compreende-se o processo pelo qual os desejos inconscientes se atualizam sobre determinados objetos, no que tange a certo tipo de relação estabelecida com eles e, eminentemente, no quadro da relação analítica. Esse mecanismo consiste em uma repetição de protótipos infantis, contudo, vivido com acentuado sentimento de atualidade. A transferência é o terreno sobre o qual se desenvolve o tratamento psicanalítico, pois se refere a sua instalação, as suas modalidades, a sua interpretação e a sua resolução (LAPLANCHE; PONTALIS, 1986). 
Em 1912, no artigo "A dinâmica da transferência", Freud aponta para características cruciais da transferência, entre elas, a capacidade de surgir como a resistência mais poderosa ao tratamento psicanalítico. De acordo com Freud, a transferência ocorre quando o material complexivo (referente ao complexo patogênico) serve para ser transferido para a figura do analista. Assim, ela produz a associação seguinte e se anuncia por sinais de resistência.

A transferência com o analista possibilita a criação de um campo discursivo que vai se delineando pelo encadeamento dos significantes produzidos tanto pelo analisante como pelo analista. No caso da criança, há que se considerar a participação dos pais nesse encadeamento. 0 campo discursivo criado, somado aos efeitos da análise com a criança sobre a estrutura familiar, com frequência, causa a demanda de trabalho dos pais ao analista. Por isso, não é de se estranhar que uma mudança na posição subjetiva da criança (provocada pelos efeitos da análise) se faça presente na estrutura como um todo, afetando os pais e provocando alterações na maneira de responder ao que há de sintomático do lado deles.

$\mathrm{Na}$ famosa carta 69, dirigida a Fliess, datada de 21 de setembro de 1897, Freud expôs suas incertezas quanto à distinção entre o que era real ou fantasia. Ele adquiriu a conviç̧ão de que não existe nenhum índice de realidade no inconsciente, de modo que não se pode distinguir entre a verdade e a ficção investida de afeto. Assim, anunciou que não acreditava mais em sua "neurótica" e, desse modo, referiu-se ao abandono do fator real como responsável pelo aspecto traumático. A partir do abandono da sua "neurótica", surgiu uma nova concepção sobre a relação entre trauma e fantasia. A noção de realidade foi deslocada para a realidade psíquica, o que levou Freud a enfatizar outros fatores como responsáveis pela etiologia da neurose.

A propósito dessa virada do pensamento de Freud, nota-se que a passagem da teoria da sedução à fantasia, além de impulsionar o deslocamento da infância para ao infantil, deu lugar à elaboração da realidade psíquica baseada no inconsciente e no desejo (FORMIGONI; GENTIL, 2016). A ruptura freudiana entre a realidade dos fatos da infância e a realidade psíquica, com a consequente mudança do registro genético e cronológico para a lógica do inconsciente, demonstra que a psicanálise opera sobre um sujeito que não tem idade, o sujeito do inconsciente. Assim, observamos que o atendimento às crianças impõe ao analista a especificidade de um posicionamento ético na medida em que, independentemente da idade cronológica, estamos sempre lidando com o sujeito do inconsciente que emerge sob transferência (PRATES, 2003).

Freud (1912) postulou que cada indivíduo alcançou um método específico de se conduzir na vida erótica através da ação combinada de sua disposição inata e das influências sofridas durante os primeiros anos de vida. Essa dinâmica produz o que se poderia descrever como um clichê estereotípico (ou diversos deles), constantemente repetidos, constantemente reimpressos no decorrer da vida da pessoa, na medida em que circunstâncias externas e a natureza dos objetos amorosos a ela acessíveis permitam. De fato, não são dinâmicas inteiramente incapazes de mudar diante de experiências recentes. Kaufmann (1996) salienta que a relação entre transferência e repetição constitui-se objeto de múltiplos debates desde Freud. Na maior parte das vezes, esses debates permaneceram prisioneiros da ideia de repetição como sinônimo aproximado de reprodução de alguma coisa passada.

Entende-se que o paciente revive, com o analista, os traumas, desejos e fantasias que está impedido de recordar devido à barreira do recalque. A expansão da clínica psicanalítica para o tratamento de crianças levou a muitas controvérsias no que diz respeito à transferência, permanecendo em constante aprimoramento. 
Segundo Checchinato (2007), o complexo sintomático da família ou da criança consiste em um conjunto de concepções subjetivas de si ou das coisas, um enredo de atitudes que um membro da família, especialmente a criança, vai repetir diante de certas circunstâncias. Possibilitar aos pais e filhos que esse mito seja desvelado, rompê-lo devido a uma nova leitura propiciada pela intervenção analítica, pode mudar de imediato o arranjo inconsciente, facultando que certos núcleos patógenos se desarticulem, se dissipem, e novas cadeias estruturem um rearranjo em que não se encontre a realimentação patógena. A partir do momento em que determinado discurso fechado passa a ser dissipado pela análise, tudo pode mudar. Esse tipo de discurso se impõe através do discurso dos pais. Não se pode perder de vista a articulação estrutural entre o sintoma infantil, o discurso familiar e o desejo parental.

O discurso familiar sela o presente com o passado, podendo surgir como empecilho ao filho de ascender ao seu próprio desejo. Para Checchinato (2007), a arte da análise com os pais consiste em detectar a(s) palavra(s) mortífera(s) e o significante encrustado, que mantém a subjetividade da criança em cativeiro.

Em "Novas conferências introdutórias à psicanálise" (1933), Freud estabeleceu uma diferença primordial entre a análise de crianças e análise de adultos. Não se trata meramente de uma descrição técnica, posto que essa diferença retoma os fundamentos da psicanálise, tratando-se da dinâmica da transferência. Com precisão, Freud afirma que, na análise de uma criança, ela tem outro papel, cuja causa se deve a presença dos pais reais. Os pais reais são os pais da infância em curso, por conseguinte, atual. Freud (1933) recomenda:

\begin{abstract}
não receamos aplicar o tratamento analítico a crianças que, ou mostraram inequívocos sintomas neuróticos, ou estavam a caminho de um desenvolvimento desfavorável do caráter (...). O que ganhamos com esses tratamentos foi havermos conseguido confirmar num ser vivo aquilo que havíamos inferido no caso dos adultos. No entanto, também para as crianças o ganho foi muito satisfatório. Verificou-se que a criança é muito propícia para o tratamento analítico, os resultados são seguros e duradouros. A técnica do tratamento usada em adultos deve, naturalmente, ser muito modificada para a sua aplicação em crianças. Uma criança é um objeto psicologicamente diferente de um adulto. De vez que não possui superego, o método da associação livre não tem muita razão de ser, a transferência (porquanto os pais reais ainda estão em evidência) desempenha um papel diferente. As resistências internas contra as quais lutamos, no caso dos adultos, são na sua maior parte substituídas, no caso das crianças, pelas dificuldades externas. Se os pais são aqueles que propriamente se constituem em veículos da resistência, o objetivo da análise e a análise como tal, muitas vezes corre perigo (FREUD, 1933, p.181).
\end{abstract}

Em consonância com o pensamento de Freud, pensamos que, na condução do trabalho com os pais, o analista oferece sua posição para que novos enigmas possam ser apresentados e abertos às intervenções analíticas. Ocupar o lugar de quem opera e dá a direção da análise é estar na posição de causar neles o desejo de trabalho e acompanhá-los nos avatares de seus complexos familiares (CARAM, 2003). Melgaço (2003) observa que o psicanalista não deve estar interessado na supressão de um sintoma, mas em transformá-lo de sintoma-resposta em sintoma-pergunta. Para a autora, o trabalho psicanalítico com crianças nos encaminha necessariamente ao trabalho com os seus pais, seguindo a direção indicada pela escuta analítica.

Flesler (2007) acredita que, ao reconhecer a infância como um tempo em curso e contemplando o fato constatável de que a presença dos pais não é algo banal ou puramente fenomenológico, mas de estrutura, Freud (1933) assinalou a especificidade da intervenção do analista com os pais, outorgando-Ihes um estatuto de influxo analítico. Todavia, essa intervenção está muito longe de psicanalisá-los.

Em uma perspectiva diferente, a propósito do texto "A técnica de análise no período de latência" (1932), de Melanie Klein, observa-se que a autora se mostrava favorável à manutenção de um contato com os pais que se restringisse ao mínimo essencial. Para Klein, o contato com os pais não deveria exceder a explicação básica sobre os significados e efeitos da análise, bem como intervenções de 
caráter mais ativo seriam utilizadas apenas quando a criança se encontrasse em risco real, ou seja, quando o ambiente cometesse para com ela erros grosseiros (SILVA; REIS, 2017).

A primazia dessa postura justificava-se por pressupor uma relação ambivalente e delicada dos pais com relação à psicanálise da criança, com os quais o ideal seria manter uma relação de cooperação e confiança. Sua aposta no sucesso do tratamento estava depositada muito mais na capacidade da criança de entrar em um processo analítico e se beneficiar dele, do que na implicação subjetiva dos pais nesse processo. Klein (1932) enfatizava ser contrária a um posicionamento pedagógico. Assim, as discussões sobre o lugar dos pais na psicanálise de crianças, por conseguinte, acompanharam o desenvolvimento da teoria e da criação de diferentes práticas, de acordo com a linha psicanalítica com a qual trabalham os psicanalistas (SILVA; REIS, 2017).

\subsection{0 manejo transferencial na clínica com crianças}

Para Flesler (2007), desde o início as crianças apresentaram um viés problemático para o psicanalista, posto que a abordagem delas demonstrou exceder o marco teórico original para o qual a psicanálise fora criada. Contudo, os problemas que essa prática nos aponta devem ser considerados intrínsecos à psicanálise de crianças ou podem ser encarados como um convite a reinterrogar os próprios conceitos nos quais se inscrevem a prática psicanalítica?

A criança chega ao consultório do analista em função das ressonâncias que gera em um adulto. Por isso, é fundamental dar lugar e importância aos acordes singulares que a criança desperta naqueles que nos procuram (FLESLER, 2007). Cabe indagar: qual o lugar ocupado pela criança no discurso e desejo parentais? Em que medida o infantil presente nos pais se atualiza na sua relação com o filho? Como a trama fantasística tecida entre pais e filho está sustentando o sintoma da criança?

Embora nenhum analista deva desconsiderar o papel dos pais enquanto presença fantasística na análise de adultos, a sua presença real na infância representa uma diferença crucial. Essa distinção entre os pais do infantil fantasístico e os pais reais da infância não se estabelece como uma substituição repentina, já que ela é construída em virtude de tempos descontínuos. Essa operação de substituição dos pais reais da infância pelos pais do infantil fantasístico não se realiza naturalmente e demandam trabalho psíquico. São muitos adultos que permanecem em dependência real dos progenitores, conservando para si uma posição de criança. Isso demonstra como essa substituição é necessária para que os pais passem a fazer parte da história infantil (FLESLER, 2007).

A dependência em relação aos pais pode manter o tempo congelado, sem sucessão. Alguma coisa não consegue se transformar em passado, continua presente, vigente, retendo uma eficácia que, longe de ser uma atualização no presente de um tempo já percorrido, perdura como presente e atual. Portanto, na clínica com crianças, há a demanda de um refinamento de escuta que contemple a presença dos pais. Os pais reais continuam presentes, porém, logo continuarão presentes não mais como pais reais da infância, e sim como os pais da fantasia (FLESLER, 2007).

Checchinato (2007) ressalta a importância de discriminar qual é a demanda dos pais e qual é a demanda do filho. A criança trazida para a análise seria efetivamente um filho? Em geral, os pais procuram pediatras e psicólogos para obter conselhos, orientações ou modos de resolver os problemas que eles averiguaram na criança. No entanto, raramente os pais conseguem observar a sua implicação no problema, mesmo estando bem intencionados e comprometidos com os cuidados infantis. Em alguns casos, os pais sentem que estão enredados na questão do filho, porém não conseguem discernir como estão enredados. Ao passo que a análise caminha, há o momento (vários momentos) em que, aos poucos, vão se dando conta disso. Por isso, o analista não precisa se preocupar que eles tenham 
ciência disso afórceps. 0 traquejo do analista experiente conduzirá cuidadosamente a escuta do que o discurso do pai ou da mãe ou de ambos veiculam.

Para Nobre (2004), convidar a criança a falar, no setting analítico, produzindo os seus significantes, é assim fazer falar do seu sintoma, da sua história, possibilitando-lhe articular suas relações primordiais, tanto na sua forma de fantasma enganoso, de engodo, quanto na forma de pergunta por aquilo que o Outro deseja. É convocar a criança, na transferência, a fazer-se sujeito, sujeito responsável. Assim, o sintoma da criança responderia, por um lado, a uma demanda inconsciente dos pais e, por outro, à sua própria escolha enquanto sujeito. Para responder ao enigma do desejo do Outro, a criança se identifica com o objeto, que, "fantasmaticamente"imagina que possa completar. A sua resposta sintomática tem a marca das suas construções enquanto sujeito, com as suas respectivas responsabilidades e implicações.

A transferência na clínica infantil, por vezes, além de ser massificada e rápida, não somente com as crianças, mas também com seus pais, em determinadas situações perpassa pelo lugar de quem os encaminha que pode ser uma autoridade de referência para a família, como o professor ou/e pediatra (BLINDER et al., 2011).

A transferência é o processo que corresponde aos desejos inconscientes que se atualizam e se apresentam sobre certos objetos com os quais se repetem matrizes infantis. A análise é na realidade a análise na transferência, por isso não é um simples conceito da técnica, é um elemento central. Sua conceituação incide na condução da análise. A transferência também inclui e envolve o analista, porque seu inconsciente, seus fenômenos de repetição, transferência e narcisismo também estão em jogo. Isso se potencializa na análise de crianças, pois se desenvolvem transferências destinadas aos pais e, às vezes, ao professor ou pediatra e não se trabalha com a "criança do adulto", ou seja, o infantil que perdura no adulto, mas com a própria criança. Esse aspecto impacta de outra maneira, mais traumática, mais angustiante, o inconsciente do analista, que se defronta de certa forma com a própria vivência originária de dependência e desamparo, com as suas ansiedades mais primitivas.

Além disso, com as crianças, a transferência não está sempre intermediada pela palavra, são produzidas ações que, às vezes, necessitam de ações como respostas. Se por um lado, o adulto repete o que viveu, por outro, a criança repete o que viveu e o que está vivendo. Há algo de contemporaneidade em sua repetição.

Os pais reatualizam seu narcisismo através da criança. No texto "Sobre o narcisismo: uma introdução" (1914), Freud pontua que o amor dos pais, tão comovedor e tão infantil, é o narcisismo dos pais renascido, transformado em amor objetal. Por essa razão, podemos dizer que a criança, "Sua Majestade, o Bebê", acarretará a revivência de aspectos infantis dos seus pais.

A neurose de transferência nem sempre se estabelece, pois é uma consequência da neurose infantil, tempo posterior a conclusão da infância. Assim, os efeitos da análise se realizam na dialética entre a criança e seus pais. Por outro lado, seu desdobramento depende do desejo dos pais e de seu enlace à castração. De nenhum outro modo eles poderiam ser transmissores da história nem relatá-la com valor de verdade. Quando na infância, se assume o encargo da transferência, sua direção aposta em promover a produção de saber no discurso. Sendo assim, os pais chegam incomodados, pois a criança feriu a imagem do narcisismo deles, e o analista terá que enfrentar o lado mais real de uma transferência que o encara com perfis francamente passionais.

Saber a causa, buscar a origem de uma aparição desagradável, desperta a criança, motivada por uma operação sem a qual nada seria possível. Se anteriormente ela teve a sorte de ser acolhida na 
ilusão dos pais, nesse outro tempo a cortina se abre para a criança e com ela o seu lugar no narcisismo dos pais. Assim, seu pensamento se aguça e seu desejo de investigar é espicaçado. Essa descoberta impulsionará a criança a procurar a fonte, a fonte do saber, que, para a criança, são os pais. Eles são o primeiro emblema tanto da crença como da suposição do saber. Com eles, amarra-se a transferência. Para eles, irá se orientar a pergunta, caso a criança não fique assustada demais. 0 psicanalista deve estar atento à forma como a criança toma "fantasmaticamente" a presença dos pais.

De acordo com Faria (2016), há uma polarização referente ao lugar dos pais na análise de crianças. Muitos autores consideram a escuta dos pais como peça fundamental para a compreensão do sintoma infantil, por isso oferecem um lugar de acolhimento e de escuta para os pais no qual o discurso do analista encontra-se a serviço da análise da criança. Por outro, há o entendimento de que a análise da criança deve ser feita de maneira independente ao discurso dos pais.

\subsection{A identificação projetiva como elemento da transferência}

O conceito de identificação projetiva, postulado por Melanie Klein, em 1946, no texto "Notas sobre alguns mecanismos esquizoides", é considerado um clássico da literatura psicanalítica, seminal, citado em quase todos os artigos sobre o assunto, como uma bandeira marcando um novo território a ser explorado, mas que, no momento da sua descoberta, não teve a dimensão do seu impacto. A identificação projetiva é um dos conceitos do arcabouço teórico-clínico kleiniano que suscitou vários outros textos e discussões a partir da sua primeira formulação. A potencialidade desse conceito foi evidenciada pelos psicanalistas que a sucederam, principalmente aqueles do seu círculo próximo: Bion, Segal e Rosenfeld, que demonstraram a amplitude da identificação projetiva tanto na dimensão teórica quanto na clínica (RIBEIRO, 2016).

De acordo com a leitura de Laplanche e Pontalis (1986), a expressão identificação projetiva foi introduzida por Melanie Klein para designar um mecanismo que se traduz por fantasmas (fantasias), em que o indivíduo introduz a sua própria pessoa, totalmente ou em parte no interior do objeto para lesá-lo, para possuí-lo ou para controlá-lo. No livro "A Psicanálise da criança" (1932), Melanie Klein já havia descrito determinados fantasmas de ataque contra o interior do corpo materno, e de intrusão sádica, perfilando o que viria a se tornar a identificação projetiva. Posteriormente, em 1946, no texto "Notas sobre alguns mecanismos esquizoides", foi concebido efetivamente o conceito de identificação projetiva como o principal mecanismo de defesa da posição esquizo-paranoide.

Esse mecanismo, estreitamente relacionado com a posição esquizo-paranoide, se configura como uma defesa primitiva, associado às ansiedades primordiais. Desse modo, ocorre a projeção fantasmática para o interior do corpo materno de partes clivadas da própria pessoa do indivíduo, e mesmo da sua totalidade (e não apenas maus objetos parciais). Esse movimento visa de alguma forma lesar e controlar a mãe a partir do interior. Esse fantasma (fantasia) é uma fonte arcaica de angústias, como a de estar preso e ser perseguido dentro do corpo materno A identificação projetiva pode, em compensação, ter como consequência que a introjeção seja sentida como uma entrada à força do exterior no interior como castigo de uma projeção violenta. Outro perigo é o ego encontrar-se enfraquecido e empobrecido na medida em que se arrisca a perder, na identificação projetiva, partes boas de si mesmo. É assim que uma instância como o ideal do ego poderia tornar-se exterior ao indivíduo (SILVA et al., 2017).

Laplanche e Pontalis (1986) compreendem a identificação projetiva como uma modalidade de projeção. Se Melanie Klein fala de identificação, é na medida em que a própria pessoa é projetada. 0 emprego kleiniano do termo "identificação projetiva" é conforme sentido estrito que tende a reservar-se em psicanálise ao termo projeção, sendo concebido como a rejeição para o exterior daquilo que o indivíduo recusa em si, projeção daquilo que é mau. 
Melanie Klein (1952) postula que, na transferência, o analisando retorna às flutuações da primeira infância entre os objetos amados, odiados, internos e externos, que dominaram seu psiquismo em suas vivências primitivas. 0 analista pode representar diversos objetos na transferência, e tais objetos não permanecem sempre os mesmos. Uma vez que a transferência é um processo dinâmico, deve-se compreender que o psicanalista pode, no tempo de uma mesma sessão, representar diversos objetos ou aspectos destes para o analisando (SILVA et al., 2017).

McCormack (2000), ao se debruçar sobre as funções primitivas da identificação projetiva, destacou algumas características fundamentais desse mecanismo de defesa. Segundo o autor, este proporcionaria o alívio da ansiedade e da dor, assim como a evitação de experiências de separação e perda. Outro aspecto salientado refere-se à capacidade de servir como veículo interno para as fantasias inconscientes de sentimentos amorosos e odiosos, ou seja, um modo bastante eficaz para que esses objetos internos sejam evacuados para o exterior. Essa evacuação pode fomentar as fantasias persecutórias que podem causar medo.

Entretanto, além de um mecanismo de defesa, a identificação projetiva funciona como uma via de adaptação, comunicação, e expressão criativa que permeia o núcleo de alguns tratamentos. Em se tratando da comunicação, a identificação projetiva representa um meio de comunicação muito primitivo que pode desencadear angústia de contratransferência no analista e subsequentes interações patológicas entre paciente e analista (Mc Cormack). Figueiredo (2002) explica que

\begin{abstract}
aquém das contra-tranferências no sentido estrito, que são respostas do analista às transferências do paciente, um aspecto essencial da dinâmica do trabalho analítico- embora seja também uma fonte de impasses-, há uma condição da possibilidade de psicanalisar- que se configura como uma contratransferência primordial, um deixar-se colocar diante do sofrimento antes mesmo de se saber do que e de quem se trata. Esta contratransferência primordial corresponde justamente à disponibilidade humana para funcionar como suporte de transferências e de outras modalidades de demandas afetivas e comportamentais profundas e primitivas, vindo a ser um deixar-se afetar e interpelar pelo sofrimento alheio no que tem de desmesurado e mesmo de incomensurável, não só de desconhecido como incompreensível. Todo o psicanalisar, no que implica lidar com as transferências-e outras coisinhas mais- depende desta contratransferência primordial (FIGUEIREDO, 2002, p. 2).
\end{abstract}

Nesse contexto, os sentimentos, pensamentos e fantasias inconscientes presentes na contratransferência podem ser demasiadamente intensos e capazes de capturar o analista, fazendo com que responda as experiências de identificação projetiva. Segundo McCormack (2000),

\begin{abstract}
the analyst's charge is to be a holding and transformative object. There are times the analyst must work through certain mental dynamics even after the patient has left the room. This is quite different than accidental or temporary holding function that sometimes occurs between the first and the last therapy session when projective identification is not fully analyzed. The analyst is often required to continue "meeting" with the patient within the context of projective identification. In the other words, long after the patient is gone, the analyst can still be struggling thorough specific internal object relations (MC CORMACK, 2000, p. 106).
\end{abstract}

Conforme o autor supracitado, cabe ao analista o encargo de ser um objeto de contenção e transformador. Porém, existem momentos em que o analista se defronta com certas dinâmicas psíquicas que fazem com que o encontro com o paciente perdure mais do que o necessário, mesmo após o paciente ter deixado a sala. Consiste em uma operação de retenção acidental, por vezes temporária, podendo ocorrer entre a primeira e a última sessão, quando a identificação projetiva não está totalmente metabolizada. Com a ativação desse dispositivo, seria estabelecido um lugar para que sejam depositados aspectos internos intoleráveis e representações de objeto de forma que estes possam ser dominados e controlados.

Wilfred R. Bion (2004) também se debruçou sobre a importância do contexto analítico, com ênfase no funcionamento psíquico do analista e ao cuidado que alguns pacientes demandam do setting. Esse autor concebeu os conceitos de rêverie e de continência, para explicar a função do analista e do enquadre analítico. A partir do conceito de identificação projetiva, Bion propôs que, para todo conteúdo 
projetado, deve haver um continente receptor. A noção de continente ou de continência relaciona-se com a capacidade da mãe ou do analista/setting de acolher as cargas projetivas do bebê ou do analisando, relacionando-se com a disponibilidade para receber um conteúdo que se apresenta na forma de uma carga projetiva (SILVA et al., 2017).

Solano (2015) explica que Bion compreendia a identificação projetiva como uma forma de comunicação primitiva entre a mãe e o bebê, capaz de persistir na vida adulta em muitas relações interpessoais, inclusive, na relação entre o analista e o paciente. 0 conceito de identificação projetiva cunhado por Klein, a partir da observação da comunicação não verbal entre mãe e bebê, foi aplicado ao cenário das relações entre analista e paciente. Inicialmente, quando um bebê demonstra desconforto através do choro ou por suas contorções, e sua mãe o ajuda a aliviar-se desse desconforto (pela amamentação, por exemplo), aos poucos se cria uma comunicação circular entre os dois. Pela repetição, essa comunicação será refinada a cada dia e, se tudo correr bem nesse processo, a mãe saberá posteriormente qual é a necessidade do bebê. Sendo assim, a identificação projetiva é denominada desse modo, pois o bebê projetou em sua mãe algo (um objeto) que era seu, e a mãe identificou-se com essas partes projetadas como se fossem dela, sentindo, pensando ou agindo de acordo.

Esse conceito está intimamente relacionado ao fato de a criança usar sua mãe como um continente provisório para sofrimentos que são intoleráveis. Essa noção ficou conhecida como relação continente/conteúdo na interação mãe-bebê. Em função da identificação projetiva, o bebê consegue manter a fantasia de estar extirpando de si (spliting off) todos os seus conteúdos desagradáveis (fome, frio, angústia, dor) e alojando-os em sua mãe. Para Bion, enquanto a mãe puder identificar-se com a angústia de seu bebê, "assumindo-a" como sua e manejando-a, o bebê tem um tempo para digerir seus impulsos e emoções brutas, transformando-os em pensamento (SOLANO, 2015).

Nesse intervalo que surgiria e se fortaleceria a capacidade de insight e pensar. Ao estender o conceito de identificação projetiva à relação analista-paciente, Bion postulou que, quando somos alvos da identificação projetiva (receptores), tal como a mãe, deveríamos funcionar como um continente provisório. Ou seja, se quisermos efetivamente tratar o paciente, precisamos desenvolver a disposição de elaborar aquilo que em nós foi por ele inoculado - por mais execrável que seja - para depois devolvermos ao paciente o que era dele, porém, de forma abrandada, metabolizada, detoxificada, uma forma que ele possa tolerar (SOLANO, 2015).

$\mathrm{Na}$ leitura de Ogden (1996), a identificação projetiva para Bion não se resume a uma fantasia inconsciente de projetar um aspecto próprio no outro e controlá-lo desde dentro. Representa um acontecimento psicológico interpessoal no qual o projetor, por via de uma interação interpessoal real com o recipiente da identificação projetiva, exerce pressão sobre o Outro para que se vivencie e se comporte de forma congruente com a fantasia projetiva onipotente.

Souza (2012) esclarece essa posição em relação à identificação projetiva afirmando que, Ogden concebe uma conceituação de um sujeito descentrado de seu lugar exclusivo, posto que se trata de um sujeito concebido como emergindo de uma dialética (um diálogo) do self e do Outro, uma subjetividade que depende da existência de dois sujeitos que, juntos, criam uma intersubjetividade por meio da qual tem origem o sujeito individual. A integração desse processo permite a introjeção de um bom objeto, um objeto capaz de conter, de significar e de simbolizar as experiências, o que faz com que novas formas de percepção do mundo estejam acessíveis, tornando possível viver o modo depressivo de organizar-se. Esse desenvolvimento representa um grande avanço do ponto de vista psíquico e do ponto de vista da experiência emocional, pois implica a possibilidade de viver a subjetividade e a historicidade. Um elemento importante na posição depressiva é a possibilidade de elaborar a culpa. Destacamos a importância de um objeto externo que sobreviva à destrutividade do bebê, da criança na clínica, dos pais, 
que possa também apresentar um mundo real - e não mágico e onipotente -, ampliando a percepção do outro e do mundo externo e interno.

Assim, retomamos o lugar do analista na clínica com crianças, que exerce de certo modo a função de continência da mãe e que pode ser pensada como algo que, em relação às identificações projetivas, torna possível acolher, conter, transformar e devolver, em doses apropriadas, os conteúdos projetados. $\mathrm{Na}$ clínica com crianças, em que se configura uma trama transferencial complexa, o analista precisa dar lugar a essas projeções e exercer uma função de continente para propiciar a elaboração desses objetos e representações.

\section{CONSIDERAÇÕES FINAIS}

A partir do que foi exposto neste artigo, notamos que a transferência é o processo que corresponde à atualização de desejos inconscientes sobre certos objetos com os quais se repetem matrizes infantis. A transferência é um elemento central da teoria psicanalítica, não um mero conceito da técnica. Por isso, podemos afirmar que a análise apenas se processa na transferência.

Na clínica com crianças, por incluir o lugar dos pais e outras particularidades inerentes ao atendimento infantil, a trama transferencial se complexifica. A transferência inclui os pais e nem sempre pode ser intermediada pela palavra. São produzidas ações que, por vezes, necessitam de intervenções como respostas. Se por um lado, o adulto repete o que viveu, por outro, a criança repete o que viveu e o que está vivendo. Há algo de contemporâneo em sua repetição.

Nesse cenário, o mecanismo da identificação projetiva, criado por Klein, em 1946, e relacionado com a posição paranoide-esquizoide, marca presença na clínica, no manejo da transferência. Enquanto elemento da contratransferência, pode produzir sentimentos e fantasias tão intensas que se inviabiliza uma intervenção adequada do analista. Portanto, no que se refere à clínica com crianças, que mobiliza e convoca o analista a se posicionar constantemente frente ao entrelaçamento de demandas dos pais e do filho, torna-se imprescindível o estudo desse mecanismo. 


\section{REFERÊNCIAS}

BION, W. R. Elementos de psicanálise. Rio de Janeiro: Imago, 2004.

BLINDER, C., KNOBEL, J., \& SIQUIER, M. L. Clínica psicanalítica com crianças. Aparecida, SP. Ideias e Letras, 2011.

CARAM, C. M. Clínica: uma criança em análise e seus efeitos no par familiar. In: MEIRA, Y. (Org.). 0 porão da família: ensaios de psicanálise. São Paulo: Casa do Psicólogo, 2003.

CHECCHINATO, D. Psicanálise de pais: criança, sintoma dos pais. Rio de Janeiro: Companhia de Freud, 2007.

DOLTO, F. A primeira entrevista em psicanálise. Rio de Janeiro: Campus, 2004.

FARIA, M. R. Introdução à psicanálise de crianças: o lugar dos pais. São Paulo: Toro editora, 2016.

FIGUEIREDO, L. C. Transferência, contratransferência e outras coisinhas mais. Trabalho apresentado em encontro da Formação Freudiana (Rio de Janeiro), 2002.

FLESLER. A. A psicanálise de crianças e o lugar dos pais. Rio de Janeiro: Ed. Zahar, 2007.

FREUD, S. A dinâmica da transferência. Edição Standard Brasileira das Obras Completas de Freud, Vol. XII. Rio de Janeiro: Imago, 1912.

Novas conferências introdutórias. Edição Standard Brasileira das Obras Completas de Freud, Vol. XXII. Rio de Janeiro: Imago, 1933.

Sobre o narcisismo: uma introdução. Edição Standard Brasileira das Obras Completas de Freud, Vol. XIV. Rio de Janeiro: Imago, 1914.

KAUFMANN, P. Dicionário enciclopédico de Psicanálise: o legado de Freud e Lacan. Rio de Janeiro: Zahar, 1996.

KLEIN, M. A Psicanálise de Crianças. Obras Completas de Melanie Klein, Vol 2. Rio de Janeiro: Imago, 1932.

KLEIN, M. Notas sobre alguns mecanismos esquizoides. Rio de Janeiro: Imago, 1946.

KLEIN, M. As origens da transferência. Inveja e gratidão e outros trabalhos. Rio de Janeiro: Imago, 1952.

LAPLANCHE, J., \& PONTALIS, J.B. Vocabulário de psicanálise. São Paulo: Martins Fontes, 1986.

MANNONI, M. A primeira entrevista em psicanálise. 6. ed. Rio de Janeiro: Campus, 2004.

MCCORMACK, C. Treating borderline states in marriage. London: Jason Aronson Inc, 2000.

NOBRE, L. Faz um laço prá mim? In: BRANDÃO, V. (Orgs.). A psicanálise e os discursos. Rio de Janeiro: Escola Letra Freudiana, 2004. 
OGDEN, T. Os sujeitos da psicanálise. São Paulo: Casa do Psicólogo, 1996.

PRATES, A. L. Constituição do sujeito e estrutura familiar. São Paulo: Cabral editora e livraria, 2003.

RIBEIRO, M. F. R. Uma reflexão conceitual entre identificação projetiva e enactment. 0 analista implicado. Cadernos de Psicanálise (CPRJ), Rio de Janeiro, v. 38, n. 35, p. 11-28, 2016. Disponível em: http://cprj. com.br/imagenscadernos/caderno35_pdf/01Uma\%20reflex\%C3\%A30\%20conceitual\%20entre\%20\%20 identifica\%C3\%A7\%C3\%A30\%20projetiva\%20e\%20enactment.pdf . Acesso em 4 de agosto de 2018.

SILVA, M. R., MARTINS, P., KRINSKI, S., GURSKI, R., \& FERRARI, A. G. (2017). Sobre a transferência na clínica psicanalítica pais-bebê. Psicologia Clínica, v. 29, n. 2, p. 193-208, 2017. Disponível em: http:// pepsic.bvsalud.org/scielo.php?script=sci_arttext\&pid=S0103-56652017000200004\&lng=pt\&tlng=pt. Acesso em 26 de junho de 2018.

SILVA, J. M., \& REIS, M. E. B. Psicoterapia psicanalítica infantil: o lugar dos pais. Temas em Psicologia, v.25, p. 235-250, 2017.

SOLANO. J. P.C. A clínica da dor crônica como ninho de pacientes difíceis: o papel da identificação projetiva. Acta Fisiátrica, v. 22, p. 43-50, 2015. Disponível em: http://www.actafisiatrica.org.br/detalhe artigo.asp?id=577. Acesso em: 4 de agosto de 2018.

SOUZA, A. S. L. Existe um lugar para os pais reais: some thoughts about the place of parents and reality in the kleinian's psychoanalysis. Estilos da Clinica, v. 17, n. 2, p. 278-289, 2012. Disponível em: http:// pepsic.bvsalud.org/scielo.php?script=sci_arttext\&pid=S1415-71282012000200007\&lng=pt\&nrm=iso \&tlng=pt. Acesso em 04 de agosto de 2018. 